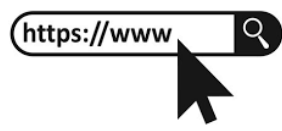

DOI: https://doi.org/10.18485/ijdrm.2021.3.1.3

\title{
INDICATORS OF RISK ASSESSMENT AND MANAGEMENT IN INFRASTRUCTURE PROJECTS IN PALESTINE
}

\author{
Mohammed Al MOUGHER ${ }^{1 *}$, Kamal MAHFUTH ${ }^{2}$ \\ ${ }^{1}$ Assistant Professor of Architecture Eengineering - Palestine University, Program of Crisis \\ and Disaster Management- IUG, Palestine, arch.moh.elmougher@gmail.com. \\ ${ }^{2}$ Research Assistant - Tunis El Manar University, Laboratory of Materials, Optimization, \\ and Energy for Sustainability (LAMOED), B.P. 37 Le Belvédère, 1002 Tunis, Tunisia. \\ Eng_kamal2015@hotmail.com
}

Funding: This research did not receive any specific grant from funding agencies in the public, commercial, or not-for-profit sectors.

\begin{abstract}
This study aims to identify the risks which face the work environment in infrastructure projects in order to reduce them and protect human and material resources also it aims to identify indicators used in the assessment, management and prevention of risks in infrastructure projects

Therefore, the study had adopted the analytical descriptive approach, which describes the phenomenon and analyse action taken and adopted in risk management and risk management approach. Infrastructure projects, there's a lack of clear application models in the governmental institutions to implement a national approach for risk management, in addition to the poor knowledge related to risk management sciences. Consequently, the study recommended to adapt comprehensive programme to qualify society and companies in the field of risk management and protection, and following the national risk management approach in infrastructure projects.
\end{abstract}

Keywords: Indicators, Assessment, Infrastructure, Projects, Palestine

\section{Introduction}

The Gaza Strip suffers from stopping of urban development because of the siege imposed on it since 2007, and depletion of material resources, environment, and diathesis infrastructure for all aspects of Palestinian development, especially after the continuation of military operations since 2006, notably attacking power station, and bridges between the Gaza and Middle Governorates, which had an impact on the environment and infrastructure of the national sectors of Palestine. As a result, The Qatar Committee for the Reconstruction of Gaza announced many projects to develop infrastructure, which is related to roads and transportation sectors, the environment, water and sanitation sector, and the social housing sector. 
Thus, 1 billion $\$$ grant was allocated by the Emir of Qatar Sheikh Hamad bin Khalifa, in addition to the grants allocated by Qatar State for the development of infrastructure which was attacked during the repeated military actions on the Gaza Strip. (El-Shaikh Ali, 2018). The risk management science is concerned with previous evaluation studies that study risk assessments and analyse their multiple impacts on different sectors. It is also concerned with the expected risks that may occur during the preparation of infrastructure projects due to its special dealings with machinery, equipment and the risks of dealing with the soil and slips expected to occur during excavations. Additionally, it concerned with the risks of materials used in projects such as hazardous chemicals which affect the human resources involved in the implementation of infrastructure projects. (Hamza, Shaimaa 2014). The planning process for Infrastructure contributes to build social, service and economic systems. Also it contributes to the achievement of comprehensive development of economic. Infrastructure development affects the recovery of the economy in various fields such as the energy sector, the water sector, the environment and sanitation sector, the transport and communications sector, the gas sector and the construction sector. Infrastructure development processes also require the development of human resources, the development of economic resources, the development of social and health services and basic services that meet the needs of the community. (Riyadh Economic Forum 2007). Hence, this research aims to identify the risks related to the work environment in infrastructure projects to reduce risks and protect human and material resources. Additionally it aims to identify indicators used in the assessment, management and prevention of risks in the infrastructure projects. The study focused on Palestine but the research procedure described in the paper may be applied to any country.

\section{Research problem}

By reviewing the meetings minuets and reports of the National Committee of Occupational Safety and Health in Palestine, the annual reports issued by the general department of inspection and work protection at Palestinian ministry of labour and the annual reports issued by Civil Defence, researcher found that there are a set of regulations and laws relating to the provision of a safe working environment but they are and have a lack in identifying clear indicators for the assessment and management risks of the work environment in infrastructure projects, Therefore, finding these indicators will provide a clear assessment that contributes to achieve the following:

a) Developing human capacity in the field of effective planning and preparation for infrastructure projects.

b) Contribute to the reduction of the work environment risks and enhance protection of workers and material resources.

c) Improve emergency response and recovery levels with minimal human and material losses.

Therefore, the research problem can be elaborated on the following main question: Can indicators of risk assessment and management in infrastructure projects contribute to the development of a safe working environment? 


\section{Objectives}

The study aims to:

- Identifying the risks related to the work environment in infrastructure projects.

- Identifying a set of indicators that can be dropped on infrastructure projects to reduce the risks of work and preserve the human and material resources, which can contribute to improving the levels of supervision of the work environment of infrastructure projects.

\section{Importance of the study:}

- Provide proposed models for the analysis and assessment of infrastructure risks projects in work environment to be used to examine the feasibility of projects implemented by infrastructure institutions.

- To develop the scientific system which researchers can rely on when we link between the indicators related to the evaluation of infrastructure risks in Palestine.

\section{Research Approach}

The study adopted a deductive approach that describes the criteria and requirements for risk management in infrastructure projects based on data collection from:

- The meetings minuets of the National Committee for Occupational Safety and Health.

- The annual reports issued by the general department of inspection and work protection.

- The annual reports issued by Civil defence

- Interview with experts.

- Visiting many projects.

It helps to describe and analyse the problem to reach the results of the study objectives, as well as the policy, criteria and indicators approach, that affect the risk study. The study was performed in 2018 and was limited to the infrastructure projects in Palestine

\subsection{Literature Review}

The literature search included standard methods (i.e. database search, including Science Direct, Google Scholar and TRIS) and the research team's extensive domestic and international contacts to find pertinent data and citations on the topic that have not been formally published. The literature search included journals, conference papers and books.

\subsubsection{Previous study}

Several previous studies have been conducted in Palestine close to this field, one of these studies is (Mughir, Muhammad, 2018) which was entitled by Indicators of Risk Assessment and Management in Industrial institutions in the Gaza Strip which aims to identify a set of indicators that can be applied to industrial institutions in occupational safety and health field. Another study is (Obaidi, Amal, 2013) which was entitled by The role of Project Risk 
Management in Ensuring the Success of its Achievement - the institution of road works and the transport of goods and fuel -Albbsa as a case study.It aims to understand the risks facing the projects and to identify the most important elements that support the effectiveness of the techniques are used to address the risks.

\subsubsection{Definitions and concepts}

Indicators: The tools defined by the institutions to measure and evaluate their achievements of objectives and vision in order to measure their plans progress. These indicators go through a set of levels according to the institution objectives, such as indicators that relate to operational activities, tactical objectives and the strategic objectives. (National Commission for Academic Evaluation and Accreditation (2013).

Evaluation: It is a management process to measure the conformity between the completed work and the institutions plan. It is determining where we stand now. The judgment of activities, events, programs and projects performed through the methodology established by the organization to measure the judgment on its outputs within the measurement models imposed by the organization.

Risk management: the level of capacity of institutions, organizations, companies, managers and employees to comprehensively understand and identify risks that are expected to cause disasters related to each sector. This entails reducing the vulnerability of damage on persons, property and the working environment by the guidelines, instructions, laws and regulations governing their management assessing the expected impact of risk. The process is carried out in several planned steps (United Nations (2015).

Danger: The problems, threats and events negatively affect the life cycle of the organization and impede the achievement of the strategic objectives. It causes a threat to both human life and environment. As well as it threated the public health, natural resources, industrial and aesthetic environment (Directorate of Policies and Studies (2016).

Risks: Threats that contribute to stopping the sustainability of the work of any project, program or plan and resulting in negative or positive impacts on the environment surrounding the sources of risk. The geographical impact varies according to the quality of the expected hazard. (Modulator, 2018).

Infrastructure: All requirements and services that operate the community, project or public utilities and facilities that contribute to the growth of the national economy (Fulmer, J, 2009). Such as transport, water, sanitation, energy and gas resources electricity, communications, roads, projects for buildings, official institutions, railways, and sports fields.

\subsection{The Current Status of Infrastructure Projects in Palestine}

Infrastructure developments in Palestine emerged after the arrival of the Palestinian National Authority at the end of 1994, when these projects were ineffectively managed and directed, especially in projects financed by international institutions where funding was mortgaged with financier policies. The occupation forces in geopolitical areas, as well as military operations and the targeting of facilities, buildings, natural and human resources since 2001, have contributed to increase significant changes in the Palestinian infrastructure. The occupation contributed also in the destruction of the f Palestinian agriculture and industrial infrastructure. It attacked housing projects and road projects and energy. In addition, it depleted the water resources, sand and natural reserves throughout the occupation of the Gaza Strip, it destructed the airport and government buildings (Esposito, Michelle, 2009). In 
2006, the indicators of destroyed infrastructure have been increased, as bridges, roads and the power plant in the Gaza Strip has been attacked. The prevalence of risk in infrastructure projects has increased as a result of the tight siege on the Gaza Strip. The environmental risks was spread due to the inability to operate many vital projects such as energy, water and sanitation. The infrastructure of all Palestinian sectors has been affected by many risks resulting from the three military attacks in 2008, 2012 and 2014, which included attacking all human, natural and industrial resources in the Gaza Strip such as electricity lines, communications networks, sewage and water, economic, social, agricultural land, fishing boats, religious and health institutions and hospitals. The rubble of the destroyed buildings spread throughout the Gaza Strip, and the waste resulting from military operations, including parts that did not explode (Modulator, 2016). so the level of challenges which faces the infrastructure in the Gaza Strip is very high as mentioned below:

- Military operations

- The siege imposed on the Gaza Strip.

- Linking project financing to external agendas from international organizations and institutions.

- The lack of interest in infrastructure projects by the state and donors, and this emerged after the military attacks on Gaza in 2014.

- The lack of real guidance for development priorities is due to the lack of clarity of the Palestinian borders.

- The depletion of natural and environmental resources in the Palestinian territories.

- Heavy pressure on infrastructure projects in light of the weak operating budgets. This has affected the direction of wastewater and sewage to the sea, increasing the marine pollution of the Gaza Strip.

- Lack of indicators to identify and assess the risks of infrastructure projects in the Gaza Strip.

\subsection{Factors Affecting increasing of Risk Levels for Infrastructure in the Palestinian Territory}

1. Military operations: The occupation destroys vital and socially sensitive facilities, resulting in huge amounts of rubble and rubble for destroyed and damaged buildings, which have a negative impact on the environment, occupational safety and health. These amounts need to remove to landfills. The occupation attacks of all available energy resources and the deforestation of agricultural land led to a high percentage of environmental pollution of water, air and soil and the high level of risk on the groundwater (Palestinian Council of Ministers, 2014).

2. Financing Risks: These risks are related to the nature of access to finance for infrastructure projects, especially since the Palestinian Territory is one of the most difficult areas to forecast the needs. The forecasting and planning of the infrastructure projects relate to the pre-security approvals for these projects, especially the energy, communications, water and sanitation projects and the local environment (El-Shaikh Ali and Ihab, 2018).

3. Selection of infrastructure locations: The signed agreements between the Palestinian National Authority and the occupation require prior security approvals for all sites chosen for the construction of the infrastructure. For example, the location of Gaza International Airport and some vital projects related to services in the border areas. 
4. Human Risks: These are all risks that can harm human staff from mismanagement of equipment, machinery, poor knowledge of the nature of the material they deal with, human injuries and accidents resulting in death risks, occupational diseases affecting employees and all human behaviours associated with the work environment (Modulator, 2018).

5. Risks of war debris: According to international reports, the military attack in 2014 resulted in approximately 7000 unexploded ordnance, in addition to the objects that exploded and left negative effects on the infrastructure, the environment, the lives of citizens and the safety of workers (Al-Mughir, 2017).

6. Environmental risks: As a result of the siege imposed on the Gaza Strip, wastewater pumped into the sea, which negatively affects the environment. Infrastructure projects and its waste disposal have affected the natural environment and its resources. All of the above, in addition to the use of hazardous and chemical materials without attention to environmental standards set by the United Nations Environment Program, as well as local standards to deal with all hazardous materials in the Gaza Strip contributed to the multiplicity of sources of danger to the environment surrounding the human, increased environmental pollution, and the spread of noise and pollution of water, air and soil (Al-Mughir, 2018).

7. Operational risk: Operational risks relate to the nature of the operation of employees and regulations that determine the rights and duties of employees, compensation requirements, working hours, hazard pay allowances, all aspects of the operational aspects of infrastructure projects, and the distribution of tasks, competencies and job descriptions for occupational safety and health supervisors, road safety inspectors, Personal safety equipment for workers in hazardous areas and insurance systems and protection of workers in dangerous areas such as tunnels, bridges and high places (ILO, 2017).

\subsection{Risk assessment and management methodology:}

There are multiple methodologies for risk management and reduction of their effects according to the variables determined by the institution for the management of the stages of risk and the implementation of the prevention strategy and methods of dealing with them.

The methodologies are multiple but agree in five the elements: the identification of risks, analysis, evaluate, control and follow-up and periodic control (Deep and Shelali, 2008).

Figure 1 shows the stages of risk assessment and management.

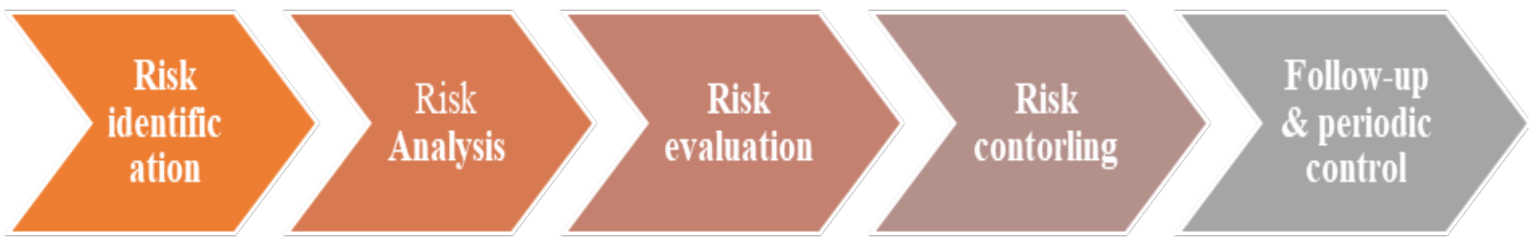

Figure 1. Stages of risk assessment and management.

\subsubsection{Risk identification:}

The methodologies for identifying and classifying risks vary from place to place, from country to country, and from institution to institution, according to their nature. There are a set of methodologies that identify risks as financial, administrative and organizational risks. Table 1 illustrates the proposed model for identifying risks. 
Table1. Proposed model to identifying Risk

\begin{tabular}{|c|c|c|c|c|c|c|c|c|}
\hline & Type of Risk & $\begin{array}{c}\text { Military } \\
\text { operations }\end{array}$ & $\begin{array}{c}\text { Financing } \\
\text { Risks }\end{array}$ & $\begin{array}{l}\text { Location } \\
\text { Selection }\end{array}$ & $\begin{array}{c}\text { Human } \\
\text { Risks }\end{array}$ & $\begin{array}{c}\text { Risks of war } \\
\text { debris }\end{array}$ & $\begin{array}{c}\text { Environmen- } \\
\text { tal risks }\end{array}$ & $\begin{array}{l}\text { Operational } \\
\text { risk }\end{array}$ \\
\hline 1 & $\begin{array}{l}\text { Nature of } \\
\text { danger }\end{array}$ & & & & & & & \\
\hline 2 & $\begin{array}{l}\text { Threat (hu- } \\
\text { man/material) }\end{array}$ & & & & & & & \\
\hline 3 & $\begin{array}{l}\text { Internal/ex- } \\
\text { ternal }\end{array}$ & & & & & & & \\
\hline 4 & Risk & & & & & & & \\
\hline 5 & Classification & & & & & & & \\
\hline & $\begin{array}{l}\text { Original and } \\
\text { target supplier }\end{array}$ & & & & & & & \\
\hline
\end{tabular}

\subsubsection{Risk analysis:}

This stage concerns with analysing the prevalence of risk and their effects, threats to be imposed and its sources, knowing the assets expected to be the target of these risks ,determination of the expected action to damage the project assets, amount of resources expected to be lost, the levels of injury caused by the core work in the project and the impact on the surrounding environment such as landslides and geological changes during the implementation of construction work (Latifa and Abdali, 2012).

\subsubsection{Risk assessment}

The ability to determine the portability of the occurrence of the hazard and its transform to a real risk that threat the implementation of the project, and causes delay in its timetable

Therefore, Risk Assessments of incidents are carried out through evaluation models organized by institutions according to risk prevalence indicators. Models are also interested in identifying risk levels (extreme, large, medium or low) to identify how to control all risks in the work sites. (Atef, et al., 2008).

At this stage, the risk is assessed according to a clear methodology as shown in table (2), which illustrates the proposed model Risk assessment indicators and probability of occurrence and the impact, while figure (2) explains the factors influencing the evaluation process.

Table 2. Risk assessment indicators and probability of occurrence and impact

\begin{tabular}{|l|c|c|c|c|c|}
\hline \multirow{2}{*}{ Evaluation Matrix } & \multicolumn{5}{|c|}{ Intensity } \\
\hline Probability & Not noticeable (1) & Low (2) & Average (3) & Intense & Very intense \\
\hline Very weak (1) & 1 & 2 & 3 & 4 & 5 \\
\hline Poor (2) & 2 & 4 & 6 & 8 & 10 \\
\hline Average (3) & 3 & 6 & 9 & 12 & 15 \\
\hline Large (4) & 4 & 8 & 12 & 16 & 20 \\
\hline Very large (5) & 5 & 10 & 15 & 20 & 25 \\
\hline
\end{tabular}




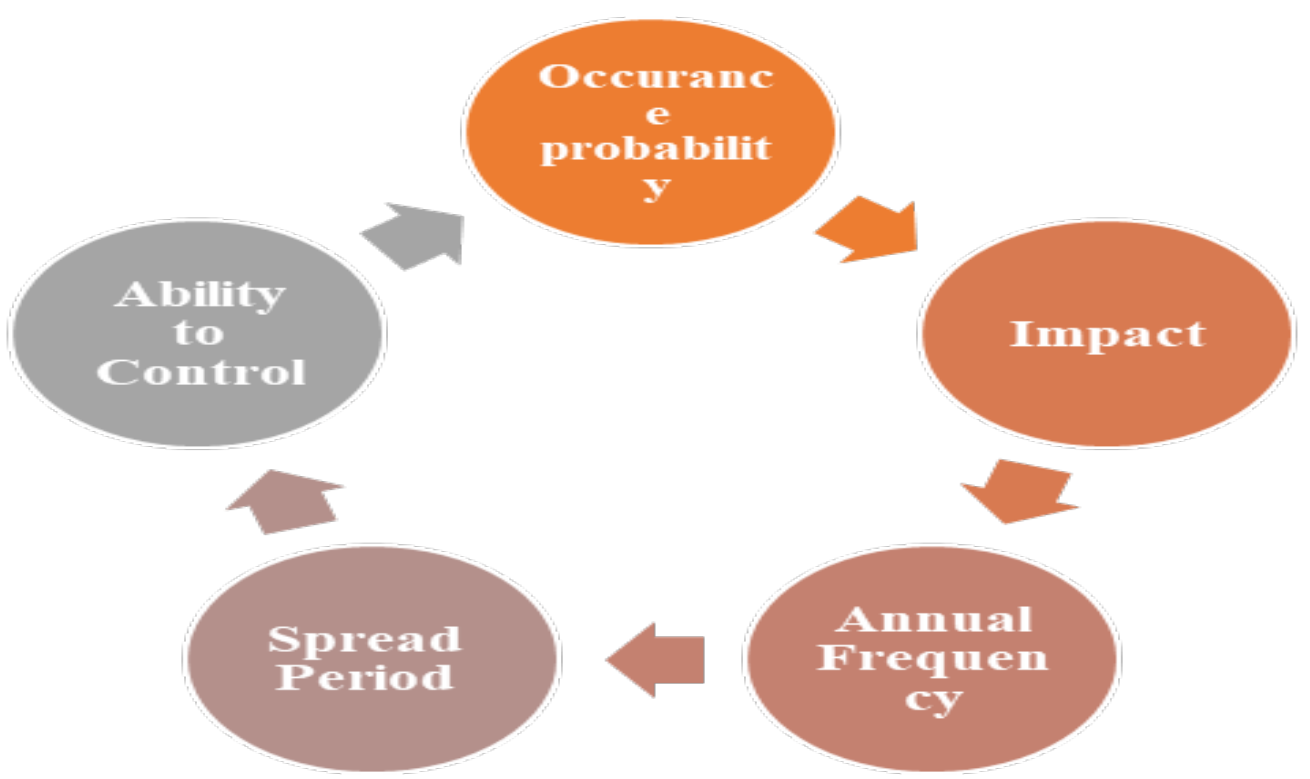

Figure 2. Factors influencing the evaluation

\subsubsection{Risk control}

The procedures used to control the threats, and measure the acceptability of the risks so that they do not have adverse effects that lead to stopping the work. Additionally, identify processes that do not require high costs, determine how to convert step paths so that the project itinerary cannot be opposed. Reducing the risk need to commitment to standards that contribute to the provision of a safe working conditions and avoiding the risk by eliminating the sources of danger and avoid them before, during or after the occurrence. The extent of control and success is determined by verifying and continues inspection on risk sources and implement to measures that reduce the risk (Latifa and Abdali, 2012). Table 3. illustrates the degrees and mechanisms of risk control.

Table2. Degrees and mechanisms of risk control

\begin{tabular}{|c|c|l|}
\hline Degree & Type & Description \\
\hline $25-15$ & Very high risk & $\begin{array}{l}\text { Very high. It can cause the stopping work in workplace under } \\
\text { the current time. It may occur loss of life, injury, material loss } \\
\text { and total disruption of work. }\end{array}$ \\
\hline 12-8 & High risk & $\begin{array}{l}\text { High and unacceptable, need to change activity and urgent } \\
\text { process, human injuries and high material losses that could } \\
\text { threaten to stop work }\end{array}$ \\
\hline $6-4$ & Medium risk & $\begin{array}{l}\text { Acceptable and must be managed so that they remain at their } \\
\text { lowest level and need to be adjusted in procedures, the rate of } \\
\text { human injuries is low and does not affect work. May be materi- } \\
\text { al losses lead to stopping work for few times. }\end{array}$ \\
\hline $3-1$ & A simple risk & $\begin{array}{l}\text { Acceptable without the need for further action. The loss of } \\
\text { human life is negligible, as well as minor material losses that do } \\
\text { not affect the work or the temporary suspension. }\end{array}$ \\
\hline
\end{tabular}




\subsubsection{Monitoring and periodic monitoring}

Direct monitoring of all changes in development plans and strategic policies related to risk management and control. These activities have contributed to the actual change of the negative coefficient impact due to the nature of the danger on the surrounding environment. Monitoring processes also include safety plans to monitor changes in risk sources, and implement all preventative actions that contribute to prevention and reduction in future (Atef, et al., 2008). For further explanation of the mechanisms for monitoring risk management evaluation and analysis, see Table 4, which outlines the integrated analysis matrix for control process of risk management.

Table 4. Integrated analysis matrix for control process of the risk management.

\begin{tabular}{|l|l|l|l|l|l|l|l|l|l|}
\hline $\begin{array}{l}\text { Type of } \\
\text { Risk }\end{array}$ & $\begin{array}{l}\text { Risk } \\
\text { status }\end{array}$ & $\begin{array}{l}\text { Risk } \\
\text { reason }\end{array}$ & $\begin{array}{l}\text { Risk } \\
\text { effect }\end{array}$ & $\begin{array}{l}\text { Level of } \\
\text { intensity }\end{array}$ & $\begin{array}{l}\text { Protection } \\
\text { requirements }\end{array}$ & $\begin{array}{l}\text { Probability } \\
\text { of Risk }\end{array}$ & $\begin{array}{l}\text { Control } \\
\text { the risk }\end{array}$ & $\begin{array}{l}\text { Check- } \\
\text { ing the } \\
\text { control }\end{array}$ \\
\hline 1 & Risk 1 & $\begin{array}{l}\text { Human } \\
\text { error }\end{array}$ & $\begin{array}{l}\text { Derelic- } \\
\text { tion }\end{array}$ & $\begin{array}{l}\text { Stop- } \\
\text { ping } \\
\text { work }\end{array}$ & $\begin{array}{l}\text { Extend } \\
\text { outside } \\
\text { the fac- } \\
\text { tory }\end{array}$ & $\begin{array}{l}\text { Awareness } \\
\text { and education }\end{array}$ & $\begin{array}{l}\text { Happened } \\
\text { before }\end{array}$ & $\begin{array}{l}\text { Can be } \\
\text { avoided }\end{array}$ & $\begin{array}{l}\text { Partially } \\
\text { con- } \\
\text { trolled }\end{array}$ \\
\hline
\end{tabular}

\subsection{Priorities of protection management and reducing risks in infrastructure projects}

The protection from risks is the most important priority for development in infrastructure field. The planning and preparation of infrastructure projects requires examining all society stress and its resources and how to sustain and protect them. The priorities in four stages:

\subsubsection{Understanding Risks}

At this stage, all risks that are expected to disrupt the operation of infrastructure projects should be understood. Risk understanding begins with understanding the threats of social and economic structure as well as understanding of operational risks that are exposed to workers, and all the risks that affect the elements of infrastructure(Water, electricity, sanitation, land use distribution, roads and transport, economic structure, social, cultural and health infrastructure, administrative and legal structure).

All of this contributes to a thorough understanding of everything that affects local infrastructure (Hamza and Shamma, 2014). Understanding risk includes:

- Risk identification: identify the risks and their distribution according to sectors that interfere in the implementation of infrastructure projects by using the tables identified by the researchers.

- Risk analysis: identify the recurrence of risks to the infrastructure, the surrounding environment and the level of injuries during the implementation of infrastructure projects and rates of material and human losses.

- Risk assessment: determine the degree of impact and probability of ooccurrence and repetition to identify the amount of damage in existing resources and their implications for prolonging the life span of project implementation periods. 


\subsubsection{Strengthening disaster risk management}

This is a priority to strengthen local and human capacities in how to effectively manage risk operations through operational plans as following:

- Risk control: ability to control risk sources through: risk distribution to reduce their impact (in the case of multiple intervention), or risk pooling (which require high levels of protection and cash flow), or risk exchange through the exchange of assets of high value with a low value, or through maintain and freeze the risk through the insurance of the project.

- Risk monitoring: monitoring of the risk through the "risk monitoring plan" which identify the preventive policies set by the state in the infrastructure projects, and follow up the safety system of workers and external site and follow-up procedures for medical periodic checking of workers.

- Identification of top policies: should be a clear and available to all employees and administrative levels, and identify possible strategic alternatives to control risks before expansion, and then choose the optimal strategic alternative, according to the current situation and future variables, which contributes to the development of risk management plans.

- Identification of risk management mechanisms : identifying activities that would help to transfer risk to other areas or to avoid activities that could contribute to risk occurrence, or to undertake activities that reduce risks through programs identified by organizations which implement infrastructure projects or accept risks that cannot affect the final output of the project or impede the work.

\subsubsection{Invest in risk reduction:}

Effective institutions should form partnerships with relevant national and local actors that require them to promote a participatory approach to investment development in disaster risk reduction. It can be implemented through:

- Strengthening the capacities of the human community: through the rehabilitation of human resources and their ability to understand field changes in the workplace that increase the level of risk affecting the implementation of the infrastructure project.

- Enhancing human capabilities and relying on informed human staff at all risk minimizes unnecessary operational costs and limits the disruption of normal activities.

- Strengthening physical capacities and infrastructure: the development of material resources and the provision of financial inputs contribute to the minimizing of risks. The strengthening of the material resources within the work site from monitoring all the executive works leads to the spread of the safety plan. The above requires agencies responsible for the implementation of projects to involve the Ministry of Labor in the prevention of risks and arrange workshops within the site in accordance with the International Labor Organization standards and the regulations of engineering work.

- Determine the geographic range of each incoming hazard: during the planning process and the preparation of infrastructure designs, the consultant is required to determine the effective geographic range of each future hazard during the implementation of the infrastructure projects. These reports shall be approved by the General Directorate of Civil Defence, inspection and work protection in the Ministry of Labor.

- Identify risk requirements and needs: during planning operations there is imperative safety plan within the work site include: distribution of all raw materials and hazardous in the workshops, generator and machinery, identify all requirements for 
safe handling of risks resulting from the use of equipment, machines and urgent intervention to prevent hazards from falling through the team dealing with accidents associated with the relevant authorities and trained in the field.

\subsubsection{Enhanced readiness to address and respond to disasters}

Planning, needs, development and development processes require us to consider all risks and involve the risk plan within the development plan, as well as to improve the readiness of the infrastructure to sustain its readiness to meet the expected risks of turning to real accidents and disasters. This is done by:

- Risk Preparedness: through good preparation based on identifying needs and expected results and where we want to get with the lowest possible cost.

- Effective planning to address risks: the efficiency of planning contributes to higher output quality as well as reducing cost related risk management.

- Distribution of tasks and roles to institutions: By defining the network of powers of all operating companies, design offices, advisory bodies, project sponsors and those who will benefit from the project.

- Training and Community Rehabilitation: Training of all human resources contributes to a clear understanding of the risks that are expected to occur. Thus, the training and qualification of the team should be designed based on direct observation in the first period of the project, and the creation of potenial risks to know how to deal with them.

- Identify the difference of confrontation and effective communication: The formation of a team to intervene directly to deal with any incident within the work site until the presence of the competent authorities and deal with those incidents. They must have direct communication equipment with government agencies that document accidents and arrange all transactions with insurance companies and other government institutions.

- Forming volunteer teams: in the event of the spread of accidents outside the work environment and can affect the human resources and physical presence in the workplace, especially the work related to major projects, coordination with the youth organizations to provide services to evacuate the workers from the place.

- The existence of an incident communication system: in the multiplicity of infrastructure projects, it is necessary to develop horizontal and vertical communication system with all levels which contribute in protecting the working human resource. Additionally, the type of communication with the government agencies concerned with emergency response operations in the event of multiple accidents and their impact is greater than the capacity of the executing company.

- Accident Response: The time factor is one of the most important factors affecting incident response. Thus, accident response processes are related to the qualification of the staff and the specialized teams working within the infrastructure projects site,s as well as to the emergency response government institutions.

- Early recovery mechanisms: in case of the spread of risks within the work site and change the parameters of infrastructure and available financial resources, it requires government agencies to support small businesses to re-regularize the work as outlined in the national policy agenda on sustainable development and within the sixth national priority (Palestinian National Policy Agenda 2017-2020). 
- Better Reconstruction: frequent incidents contribute to the reconstruction of work sites to provide a safe, decent and fair working environment that takes into account all the standards of occupational safety and health, environmental protection and the development of material and human resources.

\subsection{Integrated risk management methodology in infrastructure projects:}

There are many available risk management methodologies which manage risks in an integrated manner, which require government agencies to build a national risk management system in all areas. Also, the methodology must be linked to pre-detection of risks, and identify all remedial actions associated with human behaviour in dealing with risks as well as the implementation of remedial activities for infrastructural projects that are at risk and preventative activities that contribute to comprehensive protection. The above is done through the following:

\subsubsection{Prediction of risks and crises}

Effective organizations need to predict all risks expected to occur prior to the implementation of infrastructure projects. This requires a study of all the vulnerabilities and threats faced by the previous infrastructure projects within the local geographical areas as mentioned below:

- Infrastructure readiness to natural hazards: the first process that needs to be addressed is the preparedness of flood infrastructure. In this context, and researchers -based on their work experience in many emergency committees and local bodieshad found that the establishment of infrastructure does not take into account the requirements of comprehensive rehabilitation of all the risks expected due to high rainfall. Infrastructure that does not tolerate rainfall in unusual weather hours.

- Infrastructure readiness for industrial and human risks: it relates to the provision of infrastructure for risk response operations, as providing emergency vehicle traffic routes, the ability of the infrastructure to withstand the vibration resulting from the military actions by the occupation forces, in addition to the impact of the attacks on the destruction of many Palestinian infrastructure facilities.

\subsubsection{Planning and dealing strategies:}

- Defining the future vision: imagine what level and position we can reach in the process of defining the vision, all the expected variables are examined in relation to financial resources and natural resources. In addition to the pressure on road networks and conflicts in land use and the requirements of regulation and rehabilitation of existing infrastructure.

- Understanding Risks: This phase begins with urban planning levels during the preparation of the master plan, as well as in national and local development plans. It examines all the risks that are expected to occur and their impact on the infrastructure in the Gaza Strip and in the geographical scope of each local authority.

- Prioritization: This is done by prioritizing the handling of infrastructure projects according to the actual needs of the community, in order to achieve less operational costs for the urban development surrounding the local communityas well as providing basic infrastructure requirements to contribute to governance and good governance. 
- Turning Priorities into Strategic Goals: Strategic objectives are being set to protect the human and material resources available at the sites of infrastructure projects, and turning all goals into tactical and operational objectives. So, risk management programs and projects are designed to contribute to the rational management of resources and reduce threats that would affect infrastructure.

Table 5: shows the data to be collected during the assessment and control of infrastructure development projects that have been built on an integrated data approach that can assist in the effective development planning of the infrastructure.

Table 5. Proposed model for all integrated data on the infrastructure project

\begin{tabular}{|c|c|c|c|}
\hline Project name & & Owner & \\
\hline Donor & & Consultant & \\
\hline The project site & & The project area & \\
\hline Infrastructure project types & & Number of employees & \\
\hline $\begin{array}{l}\text { Data sheet material used in the } \\
\text { project }\end{array}$ & Liquid & Solid & Gas \\
\hline Expected risks & & Probability of occurrence & \\
\hline External threats to the project & & Frequency range & \\
\hline Type of natural hazards & & Origin of danger & \\
\hline Expected Timing & & Expected impact on the project & \\
\hline Control level & & Control procedures & \\
\hline Monitoring & Ongoing & each activity & Specific \\
\hline Availability of monitoring devices & & $\begin{array}{c}\text { Protective and safety devices } \\
\text { are available }\end{array}$ & \\
\hline $\begin{array}{l}\text { Provide protection requirements for } \\
\text { employees }\end{array}$ & & Existing of safety supervisor & \\
\hline $\begin{array}{l}\text { Priorities of Project } \\
\text { risk management }\end{array}$ & & $\begin{array}{l}\text { Sub-Sector of the } \\
\text { infrastructure Project Sector }\end{array}$ & \\
\hline Organization for addressing the risk & $\begin{array}{c}\text { Project } \\
\text { manage- } \\
\text { ment }\end{array}$ & External experts and specialists & $\begin{array}{l}\text { Government } \\
\text { agencies }\end{array}$ \\
\hline
\end{tabular}

- $\quad$ Table 6: Priorities for dealing with risks

Table 6. Priorities for dealing with risks

\begin{tabular}{|c|c|c|c|c|c|c|}
\hline & \multirow{2}{*}{ Priority } & \multirow{2}{*}{ Risk Indicator } & \multicolumn{4}{|c|}{ Evaluation } \\
\hline & & & Yes & Ratio & No & Legal action \\
\hline 1 & \multirow{3}{*}{ Understanding Risks } & Risk identification & & & & \\
\hline 2 & & Risk analysis & & & & \\
\hline 3 & & Risk assessment & & & & \\
\hline
\end{tabular}




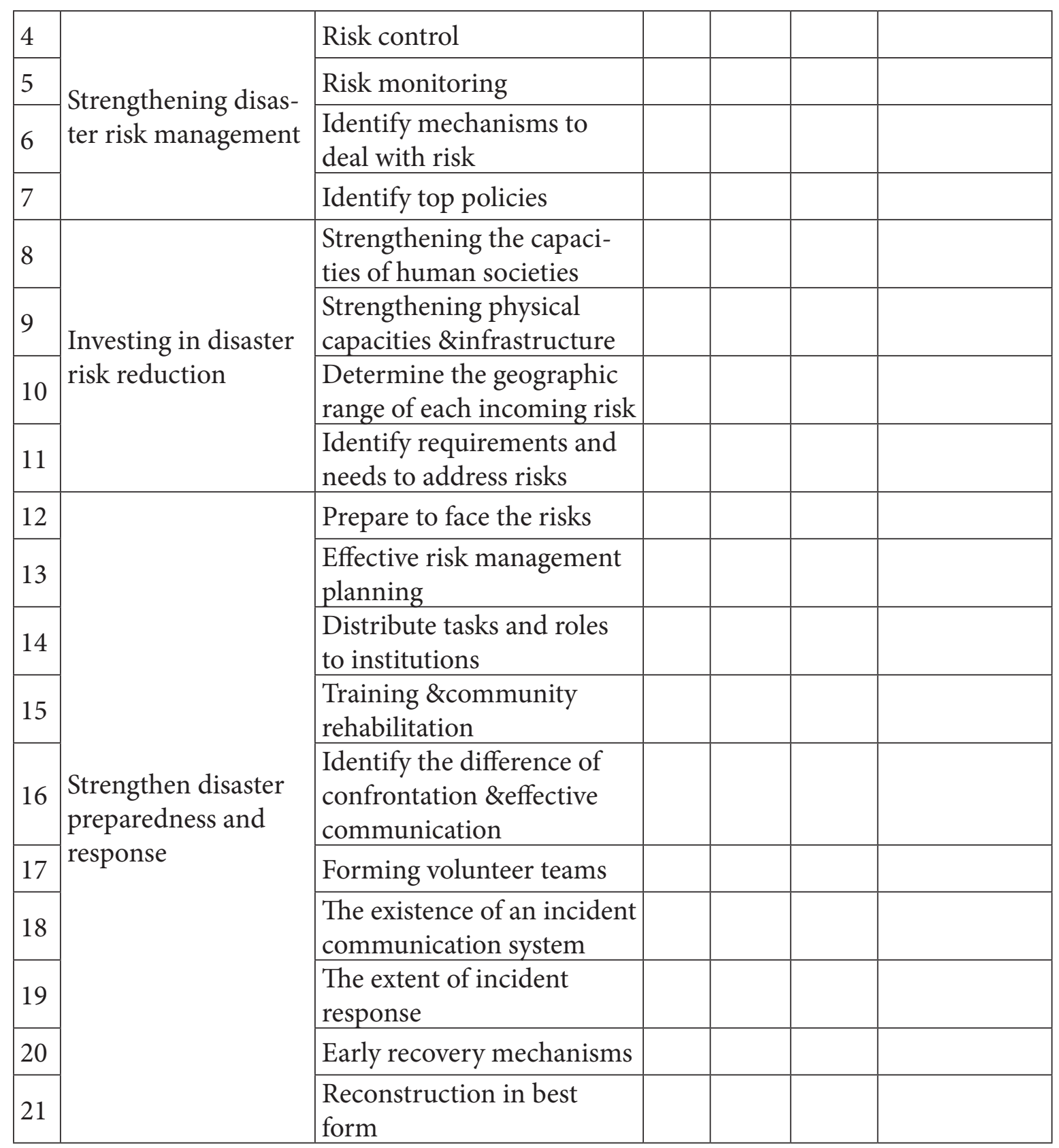

- Table 7 : shows evaluation indicators of prevention and safety measures in infrastructure projects

Table 7. Evaluation indicators of prevention and safety measures in infrastructure projects

\begin{tabular}{|l|l|l|l|l|l|}
\hline \multirow{2}{*}{ Item } & \multicolumn{3}{|l|}{ Evaluation of field safety procedures } & \multirow{2}{*}{ Notes } \\
\cline { 2 - 6 } & Excellent & Good & Average & Weak & \\
\hline Road signs in the way & & & & & \\
\hline Converts traffic paths to other routes & & & & & \\
\hline Place evacuation plan. & & & & & \\
\hline Long barriers & & & & & \\
\hline
\end{tabular}




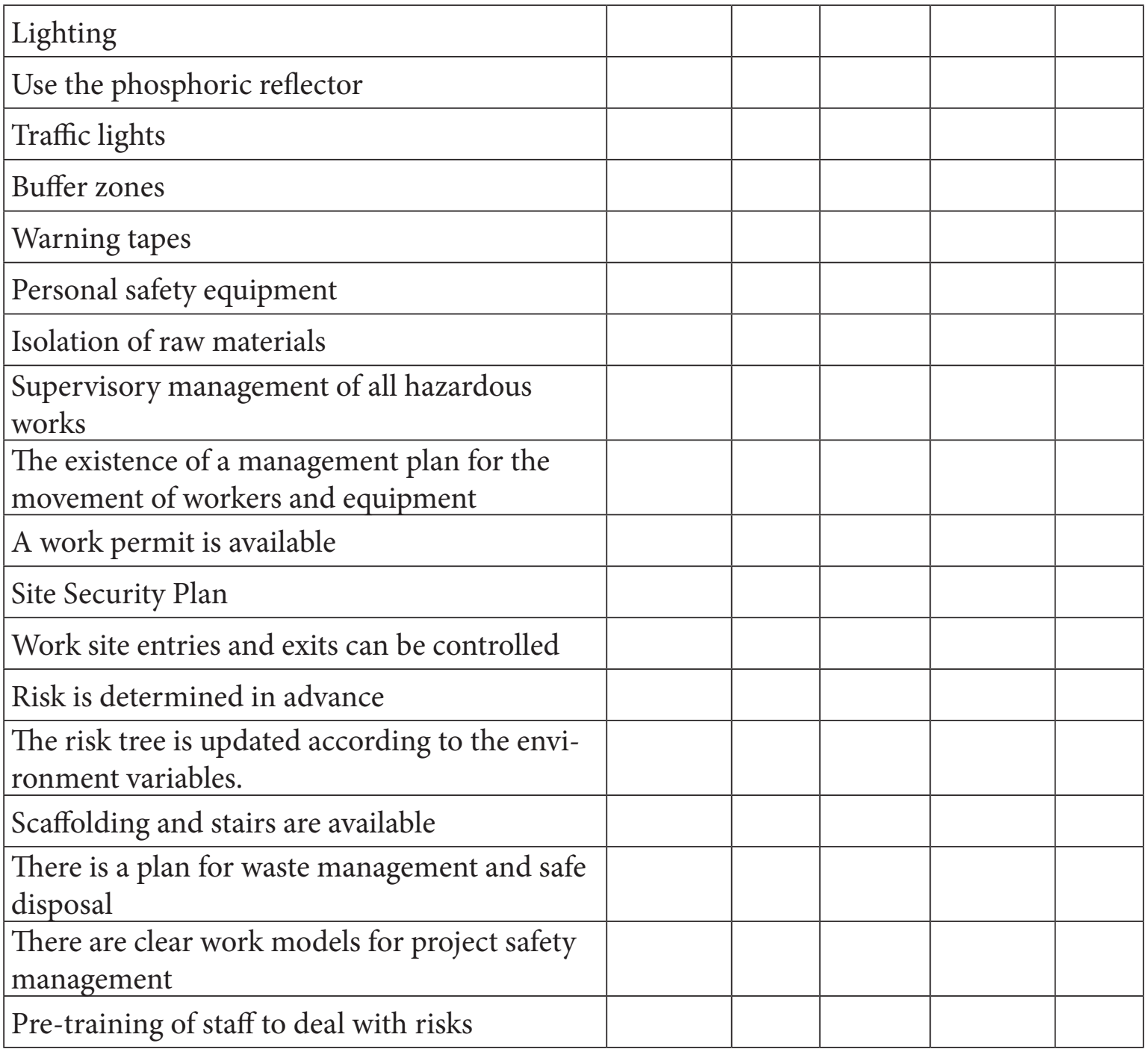

\section{Conclusion and Recommendations}

\subsection{Conclusion}

- National indicators of development in the field of infrastructure are unclear due to the lack of risk assessment, management and prioritization according to the global development methodologies.

- There is a lack of studies linking risk management and assessment in infrastructure projects.

- The cultural awareness among employees, existing of risk indicators, virtual training and creation of a hazardous environment within the workplaces can contribute effectively in managing risks in infrastructure field.

- The National Occupational Safety and Health Committee is working in enhancing the role of occupational safety and health, and integrate it into project plans to minimize losses in human resources, facilities and equipment.

- Training and community awareness of workers in infrastructure projects can play an effective role in reducing the incidence of accidents. 
- There are no documented and approved models from the National Occupational Safety and Health Committee concerned with risk analysis and assessment in the field of infrastructure.

- Lack of community awareness of risk management science in all working sectors.

- There are no clear indicators from government agencies to assess risks in the areas of infrastructure.

- Consulting companies and contracting companies can control risks if they understand risks and prioritize intervention and thus avoid them.

- There is an inverse relationship between the risk and the high rates of prevention and protection procedures employed in the workplace, which in turn reflects positively on the accident rate.

- Risk assessments, investment in risk and good preparedness to avoid risk occurrence can contribute to reducing operational costs and remedial requirements.

- Lack of interest by employers in relying on a clear methodology for risk assessment and analysis.

\subsection{Recommendations}

- It is highly recommended to direct scientific research to provide evaluation criteria and indicators that correspond to local variables in Palestine.

- Adopting the indicators included in the priority table proposed in this study by the competent authorities in the assessment and management of risks in the field of infrastructure.

- Work to increase the level of training and awareness of workers to the requirements of prevention and protection against hazards in the work environment.

- Prepare an annual risk assessment for the existing infrastructure projects and projects under implementation.

- Adopt the proposed table number 1 in prioritizing risk management.

- Adopt Proposed Table 7 in the assessment of occupational safety and health measures within the workplaces of infrastructure projects.

- Prepare an analysis of the network of risk-related relationships in the work environment and strategies for dealing with them.

- Organization quadratic planning which includes the safety plan, risk prevention, security plan, risk control, safe evacuation plan for workers, material resources and critical assets, emergency plan and the sustainability of a safe and decent working environment.

- Identify appropriate preventive activities to deal with each risk and integrate it into local and national development plans and within specific periods for each action, with the importance of monitoring of all actions and activities.

- Consulting, engineering and infrastructure companies should pay attention to training and enhance their capacity in the field of effective risk control.

- The adoption of national references for the assessment and management of risks according to the nature of the work of each sector. 
- Strengthen clear national strategies and policies in national development for infrastructure issues and projects, in order to increase their preparedness for crisis and disaster risks in Palestine.

\section{References}

1. Al-ramlawi, A. H., El-Mougher, M. M., \& Al-Agha, M. R. (2021). The Role of Al-Shifa Medical Complex Administration in Evacuation \& Sheltering Planning. Belgrade: International Journal of Disaster Risk Management, 2(2), 19-36.

2. Abdel-Moneim A. K and Mohammed, K. S, (2008). Assessment and Risk Management, Center for the Development of Postgraduate Studies and Research, Faculty of Engineering, Cairo University, First Edition, (ISBN 977-403-302-7), Egypt, pp. 10-11.

3. Abidi Amal (2013). The Role of Project Risk Management in Ensuring the Success of Achievement - Case Study of Road Works and Transport of Goods and Fuels -(Unpublished Master Thesis). Ministry of Higher Education and Scientific Research, Tebes University of, Algeria.

4. Deeb, Abdul Rashid and Chalali, Abdelkader, (2008). Strategic Approach to Risk Management, 3rd International Forum Risk Management Strategy in Institutions Prospects and Challenges, Husayya University Ben Ali AliChlef, Faculty of Economic Sciences and Management Sciences, p. 3.

5. Directorate of Policies and Studies (2016). Risk Management Strategy Ministry of Agriculture 2016-2019, Ministry of Agriculture Hashemite Kingdom of Jordan, Amman, p.8.

6. El-Shaikh Ali Ihab. (2018). The role of the Qatari fund on achieving the development priorities in Gaza Strip (Unpublished Master Thesis). Islamic University of Gaza, Palestine.

7. Esposito and Michel, 2009. Year on the Gaza War Israeli Military Operations against Gaza 2000-2008, Institute for Palestinian Studies,Palestine Studies, 20 (80-81), Beirut, Lebanon.

8. Flea Ghada, (2013). Evaluation of infrastructure projects funded by international organizations in the Gaza Strip from the point of view of partners during the period (2008-2012),(Unpublished Master Thesis). Islamic University of Gaza, Palestine.

9. Fulmer. J., (2009). What in the world is infrastructure?.PEI Infrastructure Investor (July/ August): $30-32$.

10. Hamza Shaima, (2014). Sustainability of the Infrastructure of the City of Iraq -An Analytical Study of the City of Baghdad, Iraqi Journal of Architecture, 29(3), 57-58.

11. Hamza Shaima, (2014). Sustainability of the Infrastructure of the City of Iraq, Iraqi Journal of Architecture, 29(3), 65-72.

12. Isaac, S., \& Michael, W. B. (1995). Handbook in research and evaluation: A collection of principles, methods, and strategies useful in the planning, design, and evaluation of studies in education and the behavioral sciences. Edits publishers.

13. Latifa Abdelli, (2012), The Role and Place of Risk Management in the Economic Corporation "Case Study of the Cement and Derivatives Corporation, (Unpublished Master Thesis), University of Abu Bakr Belqayd, Algeria.

14. Mughir Muhammad, (2016). Environmental Protection Plan in the Gaza Strip,(Unpublished PhD Thesis). Al-Azhar University, Cairo.

15. Mughir Muhammad, (2016). Environmental Protection Plan in the Gaza Strip,(Unpublished PhD Thesis). Al-Azhar University, Cairo, p 32-35. 
16. Mughir, M, (2017). Impact of the residues of buildings targeted to the environment in Gaza, Journal of Human Rights Generation, 22, 97.

17. Mughir, M. (2018). Indicators of Risk Assessment and Risk Management in Industrial company in the Gaza Strip, Journal of Engineering Sciences and Information Technology, 2(2).

18. Mughir, M. (2018). Indicators of Risk Assessment and Risk Management in Industrial company in the Gaza Strip, Journal of Engineering Sciences and Information Technology, 2(2). 8.

19. National Commission for Academic Evaluation and Accreditation (2013). Quality of Terms and Concepts, Deanship of Quality Assurance and Academic Accreditation, Princess NouraBint Abdul Rahman University, pp. 13-14.

20. Palestinian Cabinet, (2014). National Plan for Early Recovery and Reconstruction in Gaza, International Conference in Support of Reconstruction in Gaza, Cairo, Egypt, pp. 34-36.

21. Palestinian Central Bureau of statistics (2018): Preliminary Results of the population housing and establishments census 2017, Ramallah, state of Palestine.

22. Palestinian Ministerial Committee for the Formulation of National Policies, National Policy Agenda 2017-2020, Palestinian Council of Ministers, Ramallah, p.37.

23. Riyadh Economic Forum (2007). Integration of infrastructure is a basic requirement for sustainable development, third session, Saudi Arabia.

24. United Nations (2015) :Sendai Framework for Disaster Risk Reduction 2015-2030, the Third UN World Conference in Sendai, Japan, on March 18, 2015- United Nations Office for Disaster Risk Reduction, Sendai, Japan. 